\title{
Thermal degradation studies of LDPE containing cobalt stearate as pro-oxidant
}

\author{
P. K. Roy ${ }^{1}$, P. Surekha ${ }^{1}$, C. Rajagopal ${ }^{1}$, V. Choudhary ${ }^{2 *}$ \\ ${ }^{1}$ Centre for Fire, Explosive and Environment Safety, Timarpur, Delhi 110054, India \\ ${ }^{2}$ Centre for Polymer Science and Engineering, I.I.T, Delhi, Hauzkhas, Delhi 110016, India \\ Received 9 February 2007; accepted in revised form 18 March 2007
}

\begin{abstract}
The influence of a typical prooxidative additive, cobalt stearate, on the thermal stability, degradation kinetics and lifetime of low-density polyethylene (LDPE) was investigated using non-isothermal thermogravimetric analysis (TGA) in both nitrogen and air atmosphere. The derivative thermogravimetric (DTG) curves indicate single stage and multistage decomposition process in nitrogen and air atmosphere respectively. The kinetic parameters of degradation were evaluated using the Flynn-Wall-Ozawa iso-conversion technique. The apparent activation energies for decomposition have been calculated for degradation under nitrogen atmosphere. The lifetime of LDPE (time for 5\% mass loss) was estimated to be $8.2 \cdot 10^{26} \mathrm{~min}$ in nitrogen and was found to decrease dramatically with increase in the concentration of cobalt stearate thereby revealing its pro-oxidative ability. Studies indicated that the service/process temperature also has a strong influence on the lifetime of all the formulations investigated. The effect of cobalt stearate on the air oven aging behavior of LDPE at two different temperatures $\left(70^{\circ} \mathrm{C}\right.$ and $\left.100^{\circ} \mathrm{C}\right)$ was also investigated to demonstrate the pro-oxidative nature of cobalt stearate.
\end{abstract}

Keywords: thermal properties, LDPE, thermogravimetric analysis, thermal stability, kinetics of degradation

\section{Introduction}

The last few decades have seen a tremendous increase in the use of polyethylene, particularly in the agriculture and packaging sectors. This has resulted in its increased production and associated plastic litter problem as polyethylene in its pure form is extremely resistant to environmental degradation. It has been estimated that polyethylene would degrade less than $0.5 \%$ in 100 years, and 1\% if exposed to sunlight for 2 years before biodegradation [1]. An excellent way to render polyethylene degradable is to blend it with pro-oxidant additives, which can effectively enhance the degradability of these materials. Common pro-oxidants include transition metal salts with higher fatty acids, cobalt stearate being a typical example. We have reported in our previous studies that polyethylene containing

*Corresponding author, e-mail: veenach@hotmail.com

(C) BME-PT and GTE cobalt carboxylates exhibit a higher susceptibility to both photo as well as thermo-oxidative degradation [2-5]. However, the effect of pro-oxidant on the lifetime of polymer by non-isothermal thermogravimetry has not been investigated previously. The incorporation of these additives is expected to decrease the lifetime of polyethylene in general.

The kinetics of degradation can generate parameters, which can be subsequently used to deduce the lifetime of polymers at different temperatures. The thermal decomposition of linear polyethylene has been reported to occur via random chain scission yielding little or no monomer but many small fragments [6]. However, LDPE contains short butyl branches, which can act as weak links causing initiation to occur adjacent to these sites. It is almost impossible to obtain the exact kinetic parameters for each reaction involved in the polymer decom- 
position and apparent kinetic parameters are often used to represent the behaviour of polymer decomposition in general [7]. Actually these parameters rather represent the overall weight loss behaviour during the polymer thermal decomposition as a function of temperature.

This study is concerned with the degradation behaviour of a series of formulations containing cobalt stearate in the concentration range $(0.05-$ $0.2 \% \mathrm{w} / \mathrm{w}$ ) using non-isothermal thermogravimetric analysis in two different atmospheres: nitrogen and air. The kinetic parameters have been calculated which have been subsequently employed to predict the effect of cobalt stearate on the lifetime of LDPE. Air oven aging studies have also been performed at two different temperatures $\left(70^{\circ} \mathrm{C}\right.$ and $100^{\circ} \mathrm{C}$ ) to demonstrate practically the pro-oxidant activity of cobalt stearate on LDPE.

\section{Experimental}

\subsection{Materials}

Commercial low-density polyethylene (LDPE) (Indothene, 24FS040) was used for the preparation of films. The MFI for the polymer was $3.7 \mathrm{~g} / 10 \mathrm{~min}$ at $190^{\circ} \mathrm{C}$ under $2.16 \mathrm{~kg}$ load, with crystalline melting point of $110^{\circ} \mathrm{C}$ and density of $0.92 \mathrm{~g} / \mathrm{cm}^{3}$. Cobalt acetate, sodium hydroxide and stearic acid (AR grade, E. Merck) were used without further purification. Cobalt stearate was synthesised by double decomposition process according to the procedure reported in the literature [8]. The thermal characterisation and other physico-chemical properties of cobalt stearate have been reported in our previous papers [2-5].

\subsection{Film preparation}

Films of 70 micron thickness were prepared by mixing varying concentrations $(0.05 \%-0.2 \% \mathrm{w} / \mathrm{w})$ of cobalt stearate with LDPE using an extruder (Dayal make, Delhi, India) with a $19 \mathrm{~mm}$ screw of L:D::22:1, attached to a film blowing unit. A blow up ratio of 5.5:1 was used to prepare films. The temperature in the barrel sections of the extruder was maintained at $120^{\circ} \mathrm{C}$ and $130^{\circ} \mathrm{C}$ respectively, and that of the die head section was $135^{\circ} \mathrm{C}$.

LDPE film has been designated as F1 and LDPE containing $0.05 \%, 0.1 \%, 0.15 \%$ and $0.2 \%$ of cobalt stearate have been designated as FCS5, FCS10, FCS15 and FCS20 respectively.

\subsection{Thermal analysis}

The non isothermal thermogravimetric analysis was performed on a Perkin Elmer Diamond Simultaneous TGA-DTA-DSC. The experiments were conducted under flowing atmosphere of nitrogen and air atmosphere at a purge rate of $200 \mathrm{ml} / \mathrm{min}$. The samples were studied in the form of thin films, about $70 \pm 1 \mu \mathrm{m}$, prepared by film blowing technique. The films were sliced with a razor blade into thin oblong pieces prior to TGA analysis. A quantity of $3.5 \pm 0.3 \mathrm{mg}$ was placed in an open alumina sample pan. The sample was then equilibrated to $200^{\circ} \mathrm{C}$ before being heated to $550^{\circ} \mathrm{C}$ at different heating rates $\left(3-10^{\circ} \mathrm{C} / \mathrm{min}\right)$ for $\mathrm{TGA}$ analysis. The actual heating rate was calculated from temperature measurements made during the period of polymer decomposition. For DSC analysis, the samples were heated from $50^{\circ} \mathrm{C}$ to $200^{\circ} \mathrm{C}$ at $3^{\circ} \mathrm{C} / \mathrm{min}$

\subsection{Thermo oxidative tests}

The thermooxidative tests were carried out by placing the extruded films of F1 and FCS10 in an air oven at two different temperatures $\left(70^{\circ} \mathrm{C}\right.$ and $100^{\circ} \mathrm{C}$ ) for extended periods as reported in the literature [9]. The changes due to thermo-oxidation were monitored by recording changes in mechanical properties, structure and MFI.

Changes in the mechanical properties i.e. tensile strength and elongation at break were monitored using a Materials strength-testing machine, (JRITT25, Delhi, India). Samples with a gauge length of $100 \mathrm{~mm}$ and width of $10 \mathrm{~mm}$ were cut from the films for tensile strength measurements as per ASTM 882-85. The speed of testing was $100 \mathrm{~mm} / \mathrm{min}$. The tests were undertaken in an airconditioned environment at $20^{\circ} \mathrm{C}$ and a relative humidity of $65 \%$. Five samples were tested for each experiment and the average value has been reported.

Structural changes upon exposure were investigated using FTIR spectroscopy. Carbonyl Index (CI), as determined from FTIR spectra was used to characterize the extent of degradation in polyethylene. It is defined as the ratio of absorbance of carbonyl band around $1740 \mathrm{~cm}^{-1}$ and internal thickness band at $2020 \mathrm{~cm}^{-1}$. These have been calculated by the baseline method. 
Carbonyl Index $(\mathrm{CI})=\frac{\left.\text { Absorption at } 1740 \mathrm{~cm}^{-1} \text { (the maximum of carconyl peak }\right)}{\left.\text { Absorption at } 2020 \mathrm{~cm}^{-1} \text { (internal thickness band }\right)}$

The Melt Flow indices of all formulations before and after exposure was measured using MFI (International Equipments, Mumbai) at $190^{\circ} \mathrm{C}$ according to ASTM D1238. The extrudates were cut at regular intervals of $30 \mathrm{~s}$ after application of $2.16 \mathrm{~kg}$ of dead weight.

\section{Results and discussion}

\subsection{Thermal stability}

The melting point of LDPE, as determined from the peak of the endothermic melting transition in the DSC trace, was observed at $\sim 110^{\circ} \mathrm{C}$. It was observed that the melting point remains unaltered even after blending with cobalt stearate.

The thermogravimetric (TG) and derivative thermogravimetric (DTG) traces for FCS10 performed in nitrogen atmosphere at three different heating rates are presented in Figure 1. As is evident from the figure, all the samples exhibit single step decomposition in nitrogen atmosphere over a rela-

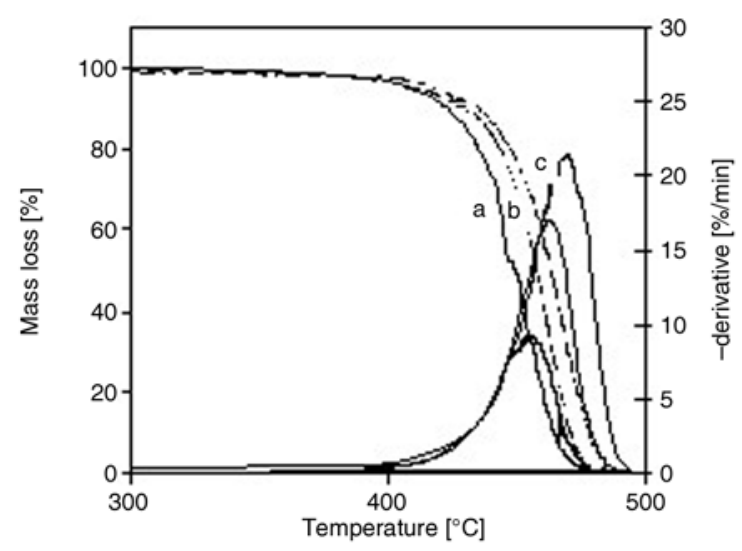

Figure 1. TG/DTG traces for the thermal decomposition of FCS10 in nitrogen atmosphere at different heating rates a) $3^{\circ} \mathrm{C} / \mathrm{min}$, b) $5^{\circ} \mathrm{C} / \mathrm{min}$, c) $7^{\circ} \mathrm{C} / \mathrm{min}$ tively short temperature range. In inert atmosphere, random scission has been reported to be the primary pathway for degradation in polyethylene [9]. However, this is also accompanied by polymer branching. From the figures, it can be concluded that both, scission as well as branching, occur simultaneously resulting in a single mass loss step. The degradation temperature was found to increase with increase in the heating rate $(\beta)$, which corresponds to the time temperature superposition principle. A shorter time is required for the sample to reach a given temperature at a faster heating rate. The onset temperature of degradation $\left(T_{\text {onset }}\right)$, temperature of maximum loss $\left(T_{\max }\right)$, end temperature of degradation $\left(T_{\text {end }}\right)$, temperature corresponding to $5 \%$ loss $\left(T_{5 l}\right)$ and $50 \%$ loss $\left(T_{50 l}\right)$ have been calculated from the DTG curves $\left(3^{\circ} \mathrm{C} / \mathrm{min}\right)$ and are presented in Table 1. It was observed that $T_{\text {onset }}$ shifts to lower temperatures with increase in the concentration of cobalt stearate, which also results in larger $\Delta T$ (difference of $T_{\text {onset }}$ and $T_{\text {end }}$ ). This also indicates that the degradation require relatively longer time periods.

In air atmosphere, a slight increase in the weight due to heating till $160-200^{\circ} \mathrm{C}$, and this has been attributed to the formation of polymeric oxides [9]. In the present investigation, a similar increase was observed in all the samples during the initial equilibration process. The increased weight at $200^{\circ} \mathrm{C}$ was read as $100 \%$ for the subsequent dynamic thermogravimetric investigations. The thermogravimetric (TG) and derivative thermogravimetric (DTG) traces for FCS10 performed in air atmosphere at three different heating rates are presented in Figure 2. Multi step decomposition was observed in air atmosphere. It is apparent that the samples start losing weight from the inception of the experi-

Table 1. Results of TG/DTG traces of films in nitrogen atmosphere and its kinetic degradation parameter

\begin{tabular}{|c|c|c|c|c|c|c|c|c|c|}
\hline Sample & $\begin{array}{l}\mathbf{T}_{\text {onset }} \\
{\left[{ }^{\circ} \mathbf{C}\right]}\end{array}$ & $\begin{array}{l}\mathbf{T}_{\max } \\
{\left[{ }^{\circ} \mathbf{C}\right]}\end{array}$ & $\begin{array}{l}\mathbf{T}_{\text {end }} \\
{\left[{ }^{\circ} \mathbf{C}\right]}\end{array}$ & $\begin{array}{c}\mathbf{T}_{\mathbf{5 l}} \\
{\left[{ }^{\circ} \mathbf{C}\right]}\end{array}$ & $\begin{array}{c}\mathbf{T}_{\mathbf{5 0 1}} \\
{\left[{ }^{\circ} \mathbf{C}\right]}\end{array}$ & $\begin{array}{c}\Delta \mathbf{T} \\
{\left[{ }^{\circ} \mathbf{C}\right]}\end{array}$ & $\begin{array}{c}\text { IPDT } \\
{\left[{ }^{\circ} \mathbf{C}\right]}\end{array}$ & n & $\ln A$ \\
\hline F1 & 401 & 456 & 486 & 406 & 449 & 84 & 449 & 0.9 & 47 \\
\hline FCS5 & 400 & 456 & 486 & 406 & 450 & 85 & 447 & 0.9 & 40 \\
\hline FCS10 & 400 & 456 & 485 & 405 & 450 & 85 & 447 & 0.9 & 15 \\
\hline FCS15 & 399 & 456 & 484 & 400 & 452 & 85 & 446 & 0.9 & 14 \\
\hline FCS20 & 390 & 457 & 482 & 400 & 453 & 92 & 445 & 0.9 & 13 \\
\hline
\end{tabular}

$T_{\text {onset }}$ : Onset temperature of degradation, $T_{\max }$ : temperature of maximum rate of mass loss, $T_{\text {end }}$ : end temperature of degradation, $T_{5 l}$ : temperature corresponding to $5 \%$ mass loss, $T_{50 l}$ : temperature corresponding to $50 \%$ mass loss, $\Delta T=T_{\text {end }}-T_{\text {onset }}$, IPDT: Integral Procedural decomposition temperature; $n$ : order of reaction, $A$ : pre-exponential factor 


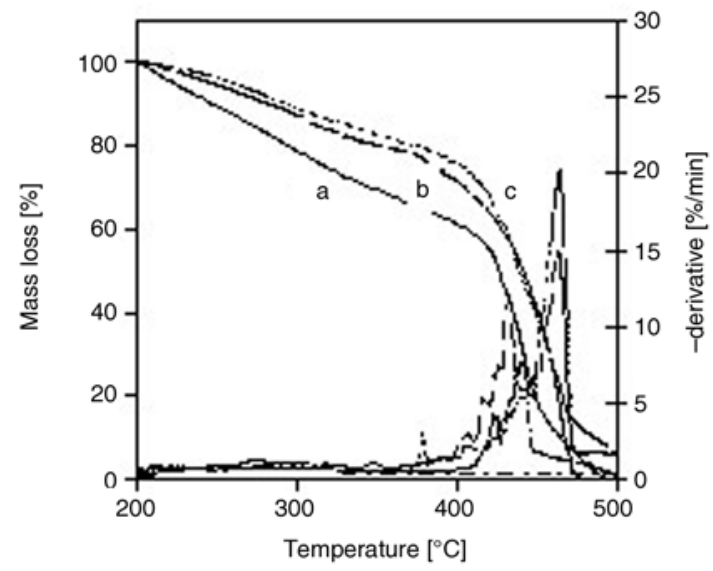

Figure 2. TG/DTG traces for the thermal decomposition of FCS10 in air atmosphere at different heating rates a) $3^{\circ} \mathrm{C} / \mathrm{min}$, b) $5^{\circ} \mathrm{C} / \mathrm{min}$, c) $7^{\circ} \mathrm{C} / \mathrm{min}$

ment after $200^{\circ} \mathrm{C}$. It is well known that the degradation of polyethylene in air occurs via reaction with oxygen [10], which results in the degradation becoming exothermic at around $\sim 400^{\circ} \mathrm{C}$. This leads to an unsteady degradation process, which does not show any systematic temperature shifts with heating rate and occurs rather randomly at this temperature $\left(\sim 400^{\circ} \mathrm{C}\right)$. Contrary to the behavior in nitrogen atmosphere, the degradation temperature was not found to increase with increase in the heating rate $(\beta)$ in air. Table 2 reports the temperature at which $5 \%$ and $50 \%$ mass loss occur's as $T_{5 l}$ and $T_{50 l}$ respectively. On comparing Table 1 and 2, we observe that the degradation occurs at much lower temperatures in air than in nitrogen atmosphere. Addition of cobalt stearate to polyethylene leads to further lowering of these characteristic temperatures, which indicate its pro-oxidative nature.

Integral Procedural Decomposition Temperature (IPDT), which sums up the shape of thermogravimetric curve, was calculated according to the method developed by Doyle [11]. The area under the thermogravimetric trace, from the initial temperature of $200^{\circ} \mathrm{C}$ to the final temperature $\left(T_{f}\right)$ of $500^{\circ} \mathrm{C}$ was determined. The ratio of this area to the total area of rectangular plot bounded by the curve

Table 2. Characteristic temperatures for thermo-oxidative degradation of polyethylene

\begin{tabular}{|l|c|c|c|c|}
\hline $\begin{array}{c}\text { Sample } \\
\text { designation }\end{array}$ & $\begin{array}{c}\mathbf{T}_{\mathbf{5 1}} \\
{\left[{ }^{\circ} \mathbf{C}\right]}\end{array}$ & $\begin{array}{c}\mathbf{T}_{\mathbf{5 0 1}} \\
{\left[{ }^{\circ} \mathbf{C}\right]}\end{array}$ & $\begin{array}{c}\text { IPDT } \\
{\left[{ }^{\circ} \mathbf{C}\right]}\end{array}$ & $\operatorname{lnA}$ \\
\hline F1 & 286 & 426 & 392 & 15 \\
\hline FCS5 & 282 & 412 & 390 & 13 \\
\hline FCS10 & 252 & 400 & 386 & 10 \\
\hline FCS15 & 267 & 400 & 385 & 7 \\
\hline FCS20 & 222 & 400 & 380 & 6 \\
\hline
\end{tabular}

gives $A^{*}$. The IPDT was obtained by employing the following relationship (1):

$\mathrm{IPDT}=A^{*}\left(T_{f}-T_{i}\right)+T_{i}$

where $T_{f}=500^{\circ} \mathrm{C}$ and $T_{i}=200^{\circ} \mathrm{C}$. The IPDT values have been reported in Table 1. The IPDT was found to decrease slightly with increase in the concentration of cobalt stearate.

As the polymers investigated in the present study consist solely of carbon and hydrogen elements, there is minimal residue once the degradation is over.

\subsection{Kinetic evaluations}

\subsubsection{Multiple constant heating rates: Flynn-Wall-Ozawa method}

The most commonly used approach to determine the apparent kinetic parameters is first to measure the weight loss behaviour during the material decomposition and then to employ the Arrhenius equation (Equation (2)) to fit this data.

$$
\frac{\mathrm{d} \alpha}{\mathrm{d} t}=A e^{-\frac{E_{a}}{R T}}(1-\alpha)^{n}
$$

where $A$ is the frequency factor, $n$ is the reaction order, $E_{a}$ is the apparent kinetic energy of the degradation reaction, $R$ is the gas constant, $\alpha$ is the conversion and $T$ is the absolute temperature. In thermogravimetric analysis, the conversion rate of a reaction is defined as the ratio of actual mass loss to the total mass loss corresponding to the degradation process (3):

$\alpha=\frac{M_{0}-M}{M_{0}-M_{f}}$

where $M, M_{0}$ and $M_{f}$ are the actual, initial and final mass of the sample respectively.

Ozawa, Flynn and coworkers [12,13] derived a method for the determination of activation energy based on the Equation (4):

$$
\log \beta \cong 0.457\left(-\frac{E_{a}}{R T}\right)+\left[\log \left(\frac{A E_{a}}{R}\right)-\log F(\alpha)-2.315\right]
$$

where $\beta$ is the heating rate. Thus, at the same conversion, the activation energy, $E_{a}$ is obtained from the plot of $\log \beta$ against $1 / T$. 


\subsubsection{Degradation kinetics in nitrogen}

Based on Equation (4), the isoconversional graph between $\log$ arithm of heating rate $(\log \beta)$ and $1 / T$ for different values of percentage conversion for FCS10 and F1 were plotted and found to be almost parallel straight lines in nitrogen atmosphere. The variation of iso-conversional activation energy with conversion for all the formulations is presented in Figure 3. For neat LDPE, the activation energy increases moderately from 250 to $280 \mathrm{kJmol}^{-1}$ throughout the degradation processes. Similar increase in the activation energy has been observed previously [14]. As has been reported by Peterson et al. [14], the observed variation in the activation energy can be attributed to the degradation kinetics being governed by different processes at the initial and final stages, the lower value of the activation energy being associated with the initial process that occur at the weak links. Low-density polyethylene is a branched polymer containing butyl branches, which can act as weak links. As these weak links are consumed, the limiting step of degradation shifts towards the degradation initiated by random scission. This type of degradation requires higher energy. The activation energy ' $E_{a}$ ' as well as frequency factor ' $A$ ' were found to decrease significantly with increase in the concentration of cobalt stearate. This indicates that cobalt stearate is capable of catalyzing the degradation process in polyethylene by providing an alternative route for degradation. During processing of polyethylene in the presence of cobalt stearate, certain intermediates may be formed which decompose first requiring a lower activation energy. During the carbonization process, the polymeric structure of

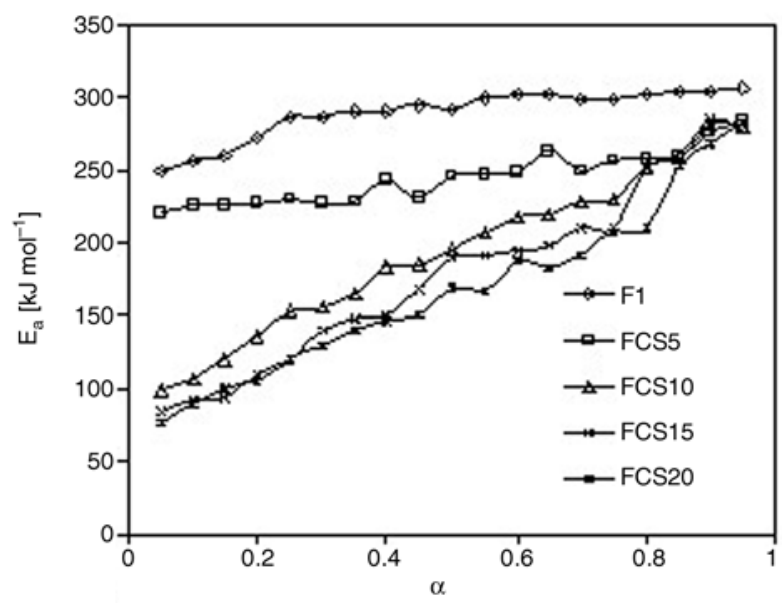

Figure 3. $E_{a}$ dependencies obtained by iso-conversional analysis of TGA data in nitrogen polyethylene breaks down, producing smaller intermediate species, which can further react and produce smaller hydrocarbon molecules, liquids and gases [15-18]. However, not every bond broken in the polymer chain leads to the evaporation of the product formed. Only the fragments small enough to evaporate at that temperature actually leave the crucible and balance records a weight loss. Both physical as well as chemical processes influence the rate of change of polymer mass and hence the degradation kinetics [19-20].

\subsubsection{Degradation kinetics in air}

The thermal degradation process in air is a very complex process and does not exhibit any systematic temperature shifts with heating rate (Figure 2). Degradation in air leads to the formation of several different products including peroxides, acids and alcohols. The initial degradation process $(\alpha<0.2)$ leads to the formation of peroxides and the calculated value of activation energy in this period $\left(\sim 80-90 \mathrm{~kJ} \mathrm{~mol}^{-1}\right)$ is consistent with the energy associated with decomposition of peroxides [14] The activation energy of PE becomes erratic thereafter. However, after the conversion reaches $20 \%$ the $E_{a}$ increases and the degradation becomes exothermic at $\sim 400^{\circ} \mathrm{C}$. This temperature is consistent with the ignition temperature of many carboxylic acids, which predominate at the later stages of degradation [14]. As a result of this random decomposition phenomenon at $\sim 400^{\circ} \mathrm{C}$, the activation energy changes erratically around the extent of conversion related to this temperature region.

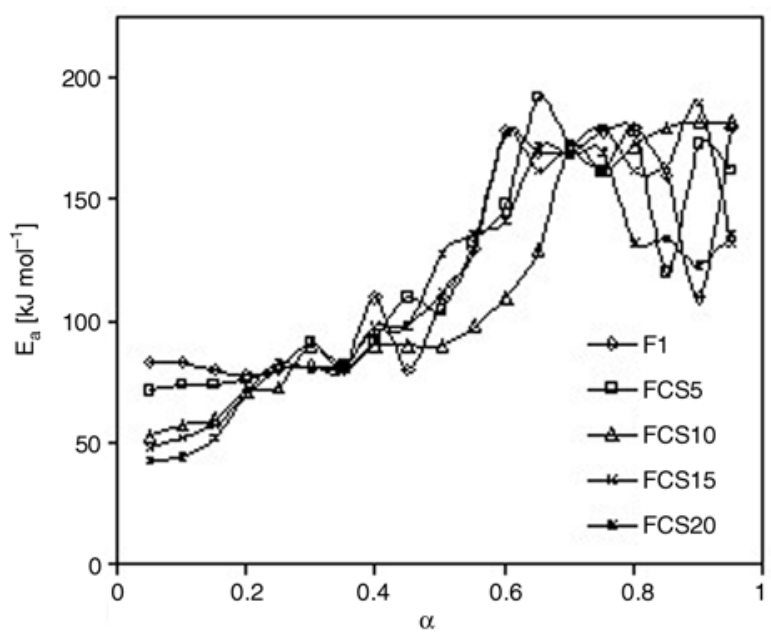

Figure 4. $E_{a}$ dependencies obtained by iso-conversional analysis of TGA data in air 
Therefore the isoconversion plots of $\log \beta$ versus $1 / T$ in air atmosphere are not parallel as in nitrogen atmosphere. The variation of iso-conversional activation energy with conversion for all the formulations in air atmosphere is presented in Figure 4. The erratic changes in $E_{a}$ indicate that the multistep decomposition in air is a complex mass loss process involving several different reactions with varied mechanisms. It is apparent that the activation energy ' $E_{a}$ ' as well as frequency factor ' $A$ ' is much lesser in air atmosphere than in nitrogen atmosphere. In the presence of cobalt stearate, the $E_{a}$ decreases and the relative lowering of $E_{a}$ is dependant on the concentration of additive thereby indicating the prooxidative ability of cobalt stearate.

\subsection{Lifetime predictions}

Lifetime estimations are very useful in the development or selection of polymers for different applications. The lifetime is usually determined by accelerated aging, like air oven aging studies, which require long time periods. The apparent kinetic parameters calculated from this study have been used to arrive at the lifetime of the formulations. The estimated lifetime of a polymer to failure has been defined as the time when the mass loss reaches $5 \mathrm{wt} \%$, i.e $\alpha=0.05$ [21-23]. From the integration of Equation (2), the lifetime can be estimated by Equation (5):

$t_{f}=\frac{\left(1-0.95^{1-n}\right)}{A(1-n)} \exp \frac{E_{a}}{R T} \quad(n \neq 1)$ or Equation (6):

$t_{f}=\frac{0.0513}{A} \exp \frac{E_{a}}{R T} \quad(n=1)$

The reaction order value $(n)$ can be obtained directly from the symmetrical index of a derivative thermogravimetry (DTG) peak based on the second Kissinger technique [23], Equation (7):

$n=1.88 \frac{\left|\frac{\mathrm{d}^{2} \alpha}{\mathrm{d} t^{2}}\right|_{L}}{\left|\frac{\mathrm{d}^{2} \alpha}{\mathrm{d} t^{2}}\right|_{R}}$

where, the indices $L$ and $R$ correspond to the left and right peak $\left(\mathrm{d}^{2} \alpha / \mathrm{d} t^{2}\right)$ values on the second derivative thermogravimetry (DDTG) curve for the decomposition process.

The $n$ and $\ln A$ values for the decomposition in nitrogen atmosphere are listed in Table 1. Using the kinetic data and Equation (4), the estimated values of lifetime in nitrogen and air atmosphere at a mass loss of 5\% at various temperatures are presented in Table 3 and 4 . The theoretically calculated lifetime in nitrogen at $25^{\circ} \mathrm{C}$ decrease from $8 \cdot 10^{26} \mathrm{~min}$ to $2.5 \cdot 10^{6} \mathrm{~min}$ as the concentration of cobalt stearate increased to $0.2 \% \mathrm{w} / \mathrm{w}$. The estimated lifetime for all compositions were substantially lesser in air atmosphere than in nitrogen atmosphere. For air atmosphere, the lifetime was predicted assuming pseudo first order reaction kinetics. It can be seen that the lifetime is strongly dependant on the serv-

Table 3. Results of lifetime as a function of service temperature in the presence of varying amounts of cobalt stearate in nitrogen atmosphere

\begin{tabular}{|l|c|c|c|c|c|c|}
\hline \multirow{2}{*}{ Sample designation } & \multicolumn{7}{|c|}{ Lifetime [minutes] } \\
\cline { 2 - 7 } & $\mathbf{2 5}^{\circ} \mathbf{C}$ & $\mathbf{7 5}^{\circ} \mathbf{C}$ & $\mathbf{1 0 0}^{\circ} \mathbf{C}$ & $\mathbf{1 2 5}^{\circ} \mathbf{C}$ & $\mathbf{1 5 0}^{\circ} \mathbf{C}$ & $\mathbf{2 0 0}^{\circ} \mathbf{C}$ \\
\hline F1 & $8.2 \cdot 10^{26}$ & $7.5 \cdot 10^{19}$ & $1.2 \cdot 10^{17}$ & $4 \cdot 10^{14}$ & $2.7 \cdot 10^{12}$ & $6.3 \cdot 10^{8}$ \\
\hline FCS5 & $1.3 \cdot 10^{20}$ & $3.5 \cdot 10^{14}$ & $2.2 \cdot 10^{12}$ & $2.3 \cdot 10^{10}$ & $4.5 \cdot 10^{8}$ & $5.7 \cdot 10^{5}$ \\
\hline FCS10 & $2.5 \cdot 10^{9}$ & $7.9 \cdot 10^{6}$ & $7.9 \cdot 10^{5}$ & $1.06 \cdot 10^{5}$ & $1.8 \cdot 10^{4}$ & $9.0 \cdot 10^{2}$ \\
\hline FCS15 & $2.4 \cdot 10^{8}$ & $1.6 \cdot 10^{6}$ & $2.2 \cdot 10^{5}$ & $3.9 \cdot 10^{4}$ & $8.5 \cdot 10^{3}$ & $6.5 \cdot 10^{2}$ \\
\hline FCS20 & $2.5 \cdot 10^{6}$ & $2.9 \cdot 10^{4}$ & $5.0 \cdot 10^{3}$ & $1.1 \cdot 10^{3}$ & $2.8 \cdot 10^{2}$ & 28 \\
\hline
\end{tabular}

Table 4. Results of lifetime as a function of service temperature in the presence of varying amounts of cobalt stearate in air atmosphere

\begin{tabular}{|l|c|c|c|c|c|c|}
\hline \multirow{2}{*}{ Sample designation } & \multicolumn{5}{|c|}{ Lifetime [minutes] } \\
\cline { 2 - 6 } & $\mathbf{2 5}^{\circ} \mathbf{C}$ & $\mathbf{7 5}^{\circ} \mathbf{C}$ & $\mathbf{1 0 0}^{\circ} \mathbf{C}$ & $\mathbf{1 2 5}^{\circ} \mathbf{C}$ & $\mathbf{1 5 0}^{\circ} \mathbf{C}$ & $\mathbf{2 0 0}^{\circ} \mathbf{C}$ \\
\hline F1 & $2.1 \cdot 10^{8}$ & $2.7 \cdot 10^{4}$ & $4.2 \cdot 10^{6}$ & $7.3 \cdot 10^{2}$ & $1.6 \cdot 10^{2}$ & $7.5 \cdot 10^{5}$ \\
\hline FCS5 & $3.9 \cdot 10^{6}$ & $6.5 \cdot 10^{3}$ & $4.3 \cdot 10^{3}$ & $2.8 \cdot 10^{2}$ & 14 \\
\hline FCS10 & $4.5 \cdot 10^{5}$ & $3.6 \cdot 10^{2}$ & $1.2 \cdot 10^{3}$ & 35 & 14 & 14 \\
\hline FCS15 & $3.5 \cdot 10^{3}$ & $3.1 \cdot 10^{2}$ & $1.1 \cdot 10^{2}$ & 11 & 5 \\
\hline FCS20 & $8.9 \cdot 10^{2}$ & $2.1 \cdot 10^{2}$ & $1.1 \cdot 10^{2}$ & 10 & 5 \\
\hline
\end{tabular}


ice temperature and decrease dramatically as the temperature increases from $25^{\circ} \mathrm{C}$ to $200^{\circ} \mathrm{C}$. To test these predictions, isothermal runs were performed in nitrogen and air atmosphere. The isothermal runs for FCS20 at different temperatures in nitrogen and air atmosphere are presented in Figure 5 and 6. It can be observed that the predictions are fairly accurate in nitrogen atmosphere especially at high temperatures but inaccurate in air atmosphere. In air, all the samples gained weight, due to the formation of polymeric oxides [9], as a function of time at lower temperatures and lost weight only at temperatures higher than melting point. From Figure 2, it is apparent that in air atmosphere, the degradation process does not exhibit any systematic temperature shifts with heating rate as a result of which the $\log \beta$ vs $1 / T$ are not parallel. This result in deviation of actual lifetime from those predicted. Moreover, the kinetics of the degradation process depends strongly on the chain mobility, which further depends on the physical state of the polymer. The chain mobility is much higher in the molten state than in the solid state thereby making the predictions even more inaccurate in the solid state.

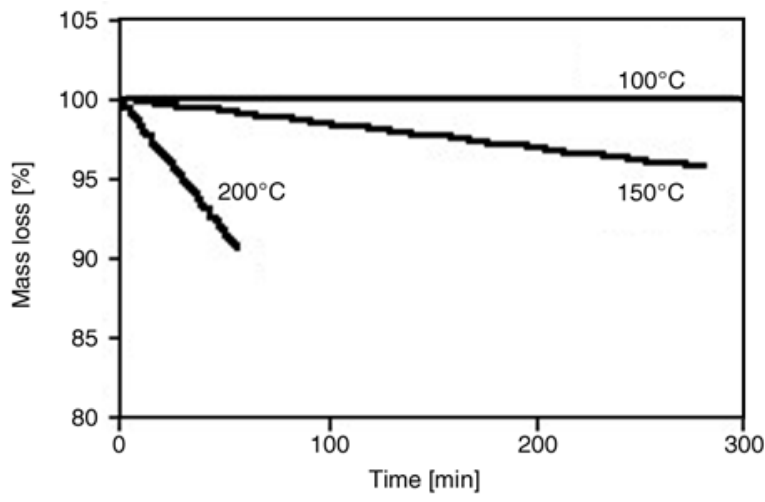

Figure 5. Isothermal runs on FCS20 in nitrogen atmosphere at different temperatures

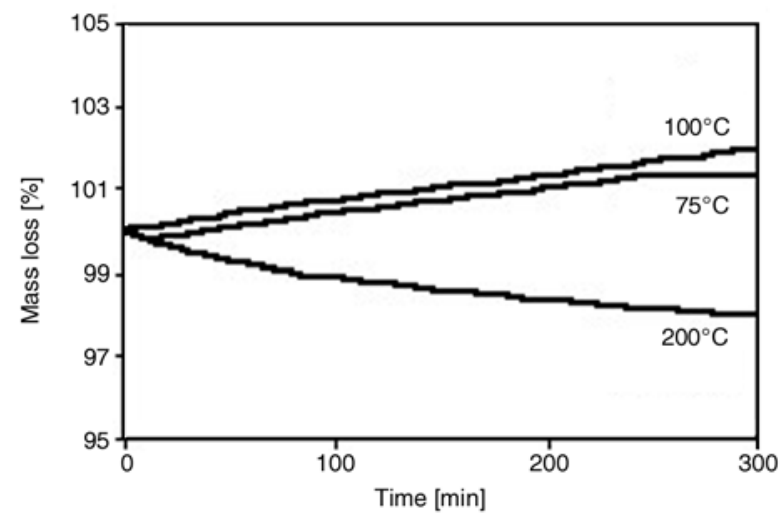

Figure 6. Isothermal runs on FCS20 in air atmosphere at different temperatures

\subsection{Air-oven aging studies}

Although the lifetime of LDPE and other formulations could not be quantified using non-isothermal technique in air atmosphere, cobalt stearate does have a strong effect on the lifetime of LDPE, and this has been demonstrated by air oven studies. Figure 7-10 depict the effect of thermal exposure (at $70^{\circ} \mathrm{C}$ and $100^{\circ} \mathrm{C}$ ) on the elongation at break and CI of F1 and FCS10 films. LDPE films have a tensile strength of $12.8 \pm 1 \mathrm{MPa}$ and elongation at break of $149 \pm 10 \mathrm{~mm}$ respectively. FCS10 also exhibits mechanical properties in the same range initially indicating that it does not lead to degradation during the processing stage. It was observed that the tensile strength does not show any decrease, however, elongation at break show a massive decrease and the same have been reported here. FCS10 films lose $~ 90 \%$ of its initial elongation after $100 \mathrm{~h}$ and $9 \mathrm{~h}$ of thermal exposure at $70^{\circ} \mathrm{C}$ and $100^{\circ} \mathrm{C}$ respectively (Figure 8 and 10). Neat LDPE films however

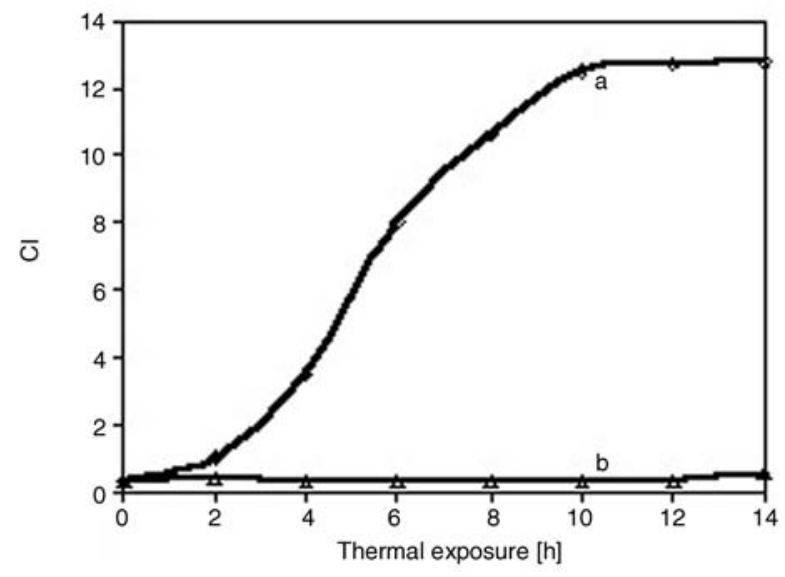

Figure 7. Variation of Carbonyl Index [CI] of a) FCS10 and b) $\mathrm{F} 1$ with thermal exposure at $100^{\circ} \mathrm{C}$

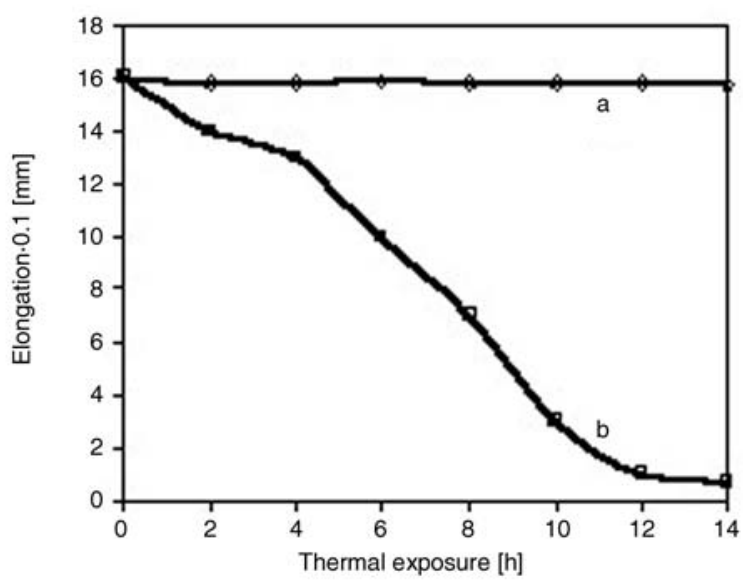

Figure 8. Variation of Elongation at break for a) F1 and b) FCS 10 with thermal exposure at $100^{\circ} \mathrm{C}$ 


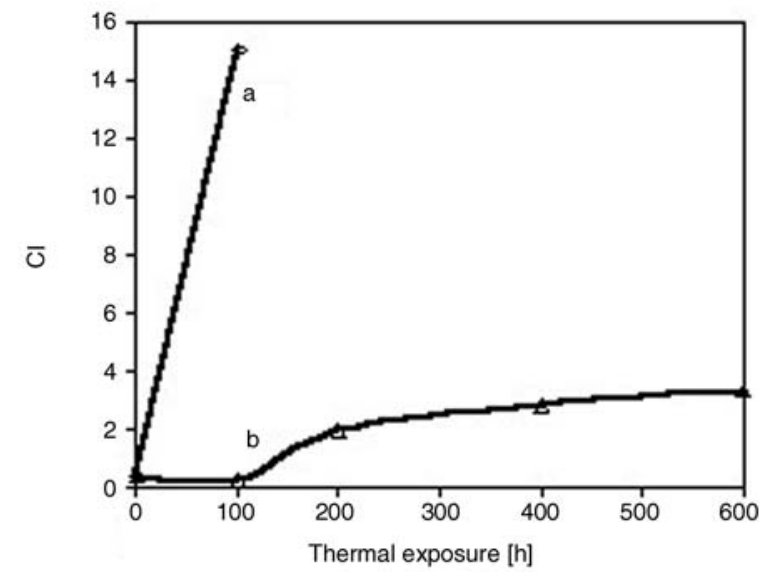

Figure 9. Variation of Carbonyl Index [CI] of a) FCS10 and b) $\mathrm{F} 1$ with thermal exposure at $70^{\circ} \mathrm{C}$

show only $60-70 \%$ loss even after $600 \mathrm{~h}$ of thermal exposure at $70^{\circ} \mathrm{C}$. Investigation of the FTIR spectra reveals that FCS10 shows significant changes in the carbonyl $\left(1785-1700 \mathrm{~cm}^{-1}\right)$, amorphous $\left(1300 \mathrm{~cm}^{-1}\right)$ and hydroxyl regions $\left(3400 \mathrm{~cm}^{-1}\right)$. The absorption band due to stretching of carbonyl group, which is centered around $1714 \mathrm{~cm}^{-1}$ grow in intensity and at the same time, a band broadening is observed which indicate the presence of numerous oxidation products like aldehydes $\left(1733 \mathrm{~cm}^{-1}\right)$, carboxylic acid groups $\left(1700 \mathrm{~cm}^{-1}\right)$ and (lactones $\left(1780 \mathrm{~cm}^{-1}\right)$ [24]. It has been reported that polyethylene films enter into the decay stage at CI greater than 6 [25]. Increase in the CI of F1 was not significant and did not reach this stage even after $600 \mathrm{~h}$ of thermal exposure at $70^{\circ} \mathrm{C}$. Samples containing cobalt stearate however had undergone significant degradation as apparent from a large increase in CI

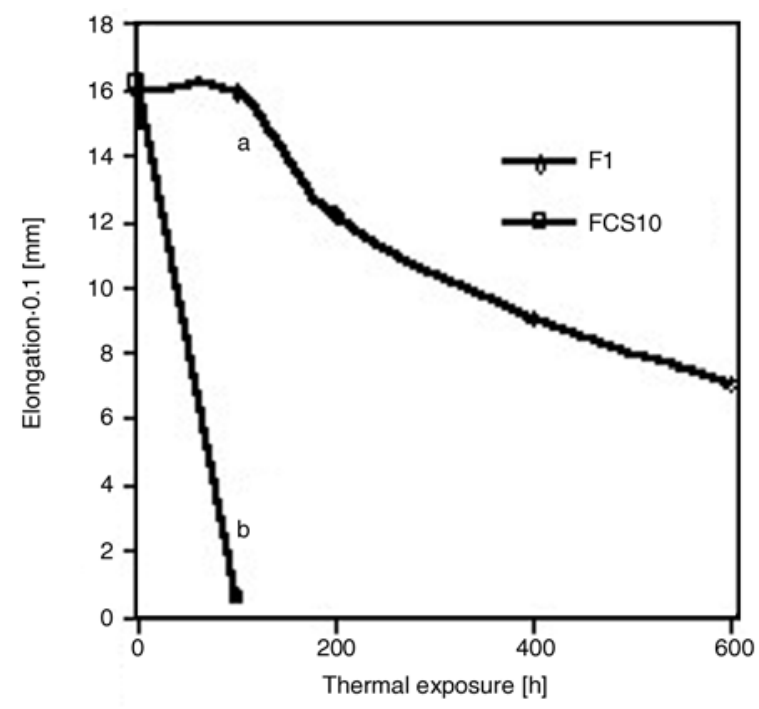

Figure 10. Variation of Elongation at break for a) F1 and b) FCS10 with thermal exposure at $70^{\circ} \mathrm{C}$ during the initial period of thermo-oxidation and the samples completely broke off after $100 \mathrm{~h}$ of exposure. The effect of air oven ageing on the MFI was also determined and it was observed that MFI for neat LDPE increased from 3.67 to 7.56 after $600 \mathrm{~h}$ of thermal exposure at $70^{\circ} \mathrm{C}$, which is indicative of chain scission resulting in lower molecular weight. The increase in MFI of FCS10 sample was much higher and could not be determined after $9 \mathrm{~h}$ of thermal exposure at $100^{\circ} \mathrm{C}$ and $\sim 100 \mathrm{~h}$ at $70^{\circ} \mathrm{C}$. The molecular weight of these films decreased drastically which affected the flow behaviour of the polymer and it flowed freely under the MFI test conditions. All these results indicate that cobalt stearate can cause rapid thermo-oxidative degradation of LDPE.

Although the pro-oxidative nature of cobalt stearate is also reflected in the non-isothermal thermogravimetric analysis, the lifetime of the polymer cannot be predicted based on empirical equations because of the non-systematic degradation of the polymer in air atmosphere.

\section{Conclusions}

The thermal stability and degradation kinetics of LDPE and formulations containing cobalt stearate as a pro-oxidant has been investigated in this paper. The apparent kinetic parameters were evaluated using Flynn-Wall-Ozawa iso-conversion technique, which has yielded the dependencies of the effective activation energy on the extent of polyethylene degradation. The activation energy was calculated from the slopes of the iso-conversion plots and was found to be much higher in nitrogen than in air atmosphere. In nitrogen atmosphere, the activation energy was found to increase with conversion and the higher values of activation energy observed in the latter stages indicate that the degradation becomes limited by degradation initiated by random chain scission. In air, the later stages of degradation are obscured by polymer ignition at $\sim 400^{\circ} \mathrm{C}$. Cobalt stearate accelerated both pyrolysis as well as thermo-oxidative degradation as indicated by lower $E_{a}$ values which indicate that in presence of cobalt stearate, the degradation follows an alternate route. The influence of cobalt stearate on the pyrolysis products was beyond the scope of this study and still needs to be addressed. Presence of even small amounts of cobalt stearate in LDPE films resulted in a significant decrease in the life- 
time. The theoretically derived values of lifetime were confirmed by isothermal runs at selected temperatures. The studies indicated that the predictions are fairly accurate in nitrogen atmosphere but fail in air atmosphere. This has been explained on the basis of irregular degradation process in air atmosphere.

\section{Acknowledgements}

The authors wish to acknowledge A. K. Kapoor, Director, Centre for Fire, Explosive and Environment Safety for providing the laboratory facilities. Thanks are also due to Dr. Raman for FTIR analysis.

\section{References}

[1] Khabbaz F., Albertsson A. C.: Rapid test methods for analyzing degradable polyolefins with a pro-oxidant system. Journal of Applied Polymer Science, 79, 2309-2316 (2001).

[2] Roy P. K., Surekha P., Rajagopal C., Raman R., Choudhary V.: Study on the degradation of low-density polyethylene in the presence of cobalt stearate and benzyl. Journal of Applied Polymer Science, 99, 236-243 (2006).

[3] Roy P. K., Surekha P., Rajagopal C., Chatterjee S. N., Choudhary V.: Effect of benzil and cobalt stearate on the aging of low-density polyethylene films. Polymer Degradation and Stability, 90, 577-585 (2005).

[4] Roy P. K., Surekha P., Rajagopal C., Chatterjee S. N., Choudhary V.: Accelerated aging of LDPE films containing cobalt complexes as prooxidants. Polymer Degradation and Stability, 91, 1791-1799 (2006).

[5] Roy P. K., Surekha P., Rajagopal C., Choudhary V.: Effect of cobalt carboxylates on the photo-oxidative degradation of low-density polyethylene. Part I. Polymer Degradation and Stability, 91, 1980-1988 (2006).

[6] Stivala S. S., Kimura J., Gabbay S. M.: Thermal Degradation and Oxidative Processes. in 'Degradation and stabilization of polymers' (ed.: Allen N. S.) Applied Science Publishers, London, 82-83 (1983).

[7] Yang J., Miranda R., Roy C.: Using the DTG curve fitting method to determine the apparent kinetic parameters of thermal decomposition of polymers. Polymer Degradation and Stability, 73, 455-461 (2001).

[8] Landau M.: Driers and Metallic Soaps. in 'Encyclopedia of Chemical Technology' (ed.: Howe-Grant M.) John Wiley \& Sons, New York, Volume 8, 432-445 (1991).

[9] Hinsken H., Moss S., Pauquet J-R., Zweifel H.: Degradation of polymers during melt processing. Polymer Degradation and Stability, 34, 279-293 (1991).
[10] Vasele C., Costea E., Odochian L.: The thermoxidative decomposition of low density polyethylene in non-isothermal conditions. Thermochimica Acta, 184, 305-311 (1991).

[11] Doyle C. D.: Estimating thermal stability of experimental polymers by Empirical thermogravimetric analysis. Analytical Chemistry, 33, 77-79 (1961).

[12] Ozawa T.: Non-isothermal kinetics and generalized time. Thermochimica Acta, 100, 109-113 (1986).

[13] Flynn J. H., Wall L. A.: A quick direct method for the determination of activation energy from thermogravimetric data. Journal of Polymer Science: B Polymer Letters, 4, 323-328 (1966).

[14] Peterson J. D., Vyazovkin S., Wight C. A.: Kinetics of the thermal and thermo-oxidative degradation of polystyrene, polyethylene and poly (propylene). Macromolecular Chemistry and Physics, 202, 775-784 (2001).

[15] Kiran Ciliz N., Ekinci E., Snape C. E.: Recycling of plastic waste via pyrolysis. Resources, Conservation. Recycling, 29, 273-283 (2000).

[16] Kiran Ciliz N., Ekinci E., Snape C. E.: Pyrolysis of virgin and waste polypropylene and its mixtures with waste polyethylene and polystyrene. Waste Management, 24, 173-181 (2004).

[17] Heikkinen J. M., Hordijk J. C., de Jong W., Spliethoff H.: Thermogravimetry as a tool to classify waste components to be used for energy generation. Journal of Analytical and Applied Pyrolysis, 71, 883-900 (2004).

[18] Dominguez A., Blanco C. G., Barriocanal C., Alvarez R., Dez M. A.: Gas chromatographic study of the volatile products from coal and polyethylene wastes. Journal of. Chromatograph A, 918, 135-144 (2001).

[19] Koo J. M., Kim S. W.: Reaction kinetic model for optimal pyrolysis of plastic waste mixtures. Waste Management Research, 11, 515-529 (1993).

[20] McCoy B. J.: Distribution kinetics for temperature programmed pyrolysis. Industrial Engineering Chemical Research, 38, 4531-4537 (1999).

[21] Wang H., Tao X., Newton E.: Thermal degradation kinetics and lifetime prediction of a luminescent conducting polymer. Polymer International, 53, 20-26 (2004).

[22] Li X. G., Huang M. R.: Thermal decomposition kinetics of thermotropic poly (oxybenzoate-co-oxynaphthoate) vectra copolyester. Polymer Degradation and Stability, 64, 81-90 (1999).

[23] Huang M. R., Li X. G.: Thermal degradation of cellulose and cellulose esters. Journal of Applied Polymer Science, 68, 293-304 (1998).

[24] Gugumus F.: Thermooxidative degradation of polyolefins in the solid state: part I. Experimental kinetics of functional group formation. Polymer Degradation and Stability, 52, 131-144 (1996).

[25] Lin Y.: Study of photooxidative degradation of LDPE film containing cerium carboxylate photosensitiser. Journal of Applied Polymer Science, 63, 811-818 (1997). 